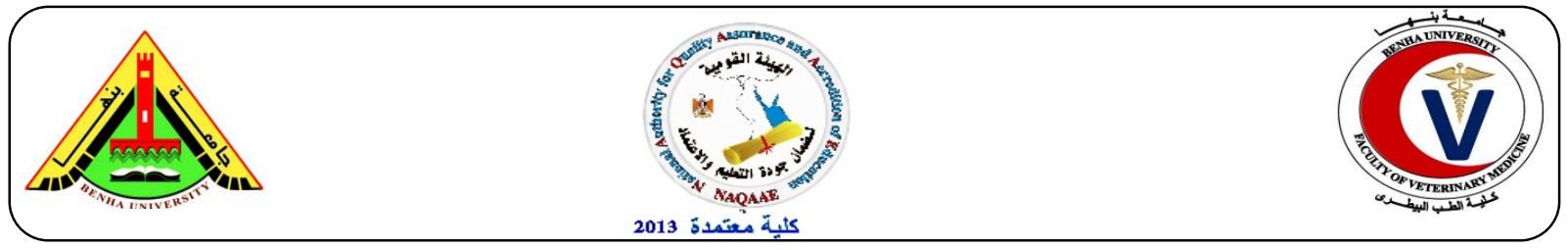

\title{
Physiological, hematological and biochemical alterations in heat stressed goats
}

\author{
Noura El- Shahat Attia
}

Department of Animal Medicine, Faculty of Veterinary Medicine, Zagazig University

\begin{abstract}
A B S T R A C T
Heat stress is one of the main factors which adversely affecting the animal welfare and thus the economic benefits of the farms. Goat husbandry in Egypt tends to breed throughout the year. However, a high ambient temperature is the major restriction on the animal productivity. This effect is provoked when heat stress is accompanied by high ambient humidity. This study was aimed to study the effect of heat stress on the physiological, some hematological and biochemical parameters. Twenty-five goats were exposed to the daytime (30 days) after an initial 7 day shading period, while another 10 goats were exposed to the shading regimen throughout the entire 30 days as a control group. Heat stressed goats showed the decrease of the feed intake, body weight and growth rate. Physiologically, the rectal temperature, respiration and heart rates were observed to be significantly higher. Moreover, the red blood cells count (RBCs), hemoglobin concentration $(\mathrm{Hb})$, and packed cell volume (PCV) were significantly increased, whereas an insignificant change in white blood cells count (WBCs). Also, the serum total proteins, albumin, glucose, urea and creatinine levels were significantly decreased. On the other hand, cortisol level were significantly increased in heat stressed goats. Our results indicated that heat stress produced a significant alteration in the physiological, some hematological and biochemical parameters.
\end{abstract}

Keywords: Heat stress, goats, physiological, Hematological, biochemical analysis

http://www.bvmj.bu.edu.eg)

(BVMJ-31(2):56 -62, 2016)

\section{INTRODUCTION}

Livestock subjects to different kinds of stress such as physical, nutritional, chemical, psychological and thermal stress. Stress is a reflex reaction of the animals in the cruel environment and causes unfavorable consequences ranges from discomfort to death of the animal. Harsh environmental conditions during summer could have a negative impact on animal condition. However, the animal being homeotherms can resist heating stress up to some extents depending on the species, breed and productivity (Al-Tamini, 2007). Heat stress is the most important climatic stress that even threatens the survival of the animals (Sejian et al., 2013). As in summer, the atmospheric temperature may rise as high as $46^{\circ} \mathrm{C}$ during day time and $30^{\circ} \mathrm{C}$ at night. The high temperature along with high humidity and increased day length (13-14 hours) aggravate the heat stress in livestock. Intergovernmental Panel on Climate Change (2007) reported that earth temperature has been increased by $0.2^{\circ} \mathrm{C}$ per decade; it also predicted that the global average surface temperature would be increased to 1.4$5.8^{\circ} \mathrm{C}$ by 2100 . Heat stress is an imbalance between heat gain and heat loss in which there is an inability to dissipate sufficient heat to maintain the homeothermy when the heat load of an animal is greater than his capacity to loss heat and the animal temperature is higher than the temperature range of the animal thermoneutral zone (TNZ). Environmental factors including the ambient temperature, relative humidity and metabolic heat produced from the maintenance and productive process contribute to the heat stress (Dash et al., 2016). Under Egyptian conditions, goats production suffered from a deficiency in nutritional requirements. The effects of these deficiencies will be aggravated when coupled with heat stress as a result of high temperature and humidity. Clinical symptoms vary according to the level of stress differ from an elevation in rectal temperature and respiration (Avendono-Reyes et al., 2011; Srikandakumar et al., 2003) heart rate, dry matter intake is decreased and ratio of forage to concentrate intake is decreased causing the decrease of growth rate, production, reproductive efficiency and profitability of animals. Water intake is significantly increased; excessive panting and restlessness are observed. Rumination and urination were decreased. Finally, when heat stress is extreme immobility or aimless wandering, staggering, drooling or slobbering, open-mouth 
breathing, sweating and increased saliva production. Then collapse, non-responsiveness, seizures and death. Exposing farm animal to high ambient temperature leads to disturbance of the normal physiological balance of the animal which, in turn, results in negative nitrogen, mineral, energy and thermal balances and lowered production. In addition, heat stress causes a disturbance in the metabolism of water, protein, energy and mineral balances, enzymatic reactions, hormonal secretions and blood metabolites (Marai et al., 2000). The fundamental aspect to reduce the effect of heat stress on animals is to change the environment through using of sheds, fans or evaporative cooling (Bucklin et al., 1991). Such practices are not possible in the semi-intensive production system of goats. Exposure of goats in open fields during most of the day hours makes them prone to heat stress despite heat resistant characteristics (Al-Tamini, 2007). Animal welfare is of an increasing importance as it is related to productivity.

Therefore, the present work aimed to determine the effect of heat stress on physiological, some hematological and biochemical parameters in goats.

\section{Materials and Methods}

\subsection{Animals:}

Thirty-five adult female, non-pregnant Zarabi goats were almost similar in weight selected for the study aged about 1.5 -2 years. The first group consisted of ten goats considered as "control group" was maintained in shaded housing facilities for the 30 days "duration of the study' while the second group "25 animals" was housed for 7 days under shading then exposed to radiation onwards during hot summer season "15 June to 15 July". The climate at this time is hot and humid. The average daily temperature was $29.2^{\circ} \mathrm{C}$, while the highest and lowest temperatures were 43 and $23^{\circ} \mathrm{C}$, respectively. Maximum and minimum temperature was measured by using maximum minimum thermometer.

\subsection{Clinical Examination}

All goats were subjected to thorough clinical examination according to the method of Jackson and Cockcroft (2008). Physiological measurements (rectal temperature, respiration and heart rate) were recorded.

\subsection{Haemato-biochemical analysis}

Two blood samples were collected via jugular vein puncture. The first sample, about $2 \mathrm{ml}$ of blood was transferred into vacuum ethylene diamine tetra acetic acid coated tubes for hematological parameters including hemoglobin (Hb), packed cell volume (PCV), total erythrocyte count (TEC) and total leukocyte count (TLC), which were estimated within 2-4 h of collection by fully automated hematology cell counter. The second sample, $10 \mathrm{ml}$ of blood without anticoagulant to yield serum which was separated by centrifugation at $3000 \mathrm{rpm}$ for 15 minutes, was decanted into Eppendorf tubes and stored at $-20^{\circ} \mathrm{C}$ pending biochemical analysis.

Serum total proteins, albumin, AST, ALT, urea and creatinine were determined colorimetrically using available kits spectrophotometrically according to the manufacturer's instructions, The commercial kits used were provided by Biomerieux, Egypt. Cortisol was measured by radioimmunoassay (Reuter et al., 1978). Serum glucose was estimated colorimetrically according to Sugiura and Hirano (1977).

\subsection{Statistical analysis}

For presentation of the results the means and their standard error means (SEM) were calculated. The results were subjected to Student's t-test according to the method described by Snedecor and Cochran (1989) using the Statistical Analysis System software. The results were considered statistically significant when $P<0.05$.

\section{RESULTS}

Clinically, the affected animals were depressed. There was a decrease in feed intake and increase the desire for drinking water. In advanced cases, there was salivation, prostration and finally recumbency. Physiological responses, including rectal temperature, respiration and heart rates have been presented in Figure 1. They were significantly increased $(P<0.01)$ as a function of exposing the animals to heat stress. Hematological parameters revealed a significant increase of $\mathrm{Hb}$ content, PCV\%, RBCs while, WBCs has not significantly changed as in Figure 2.

On the other hand, the serum biochemical analysis of heat stressed goats for liver and kidney functions revealed non-significant decrease in each of AST, ALT and a significant decrease of total proteins, albumin, glucose, urea and creatinine in relation to the control group, moreover, a significant increase of cortisol level as shown in Figure 3\&4. 


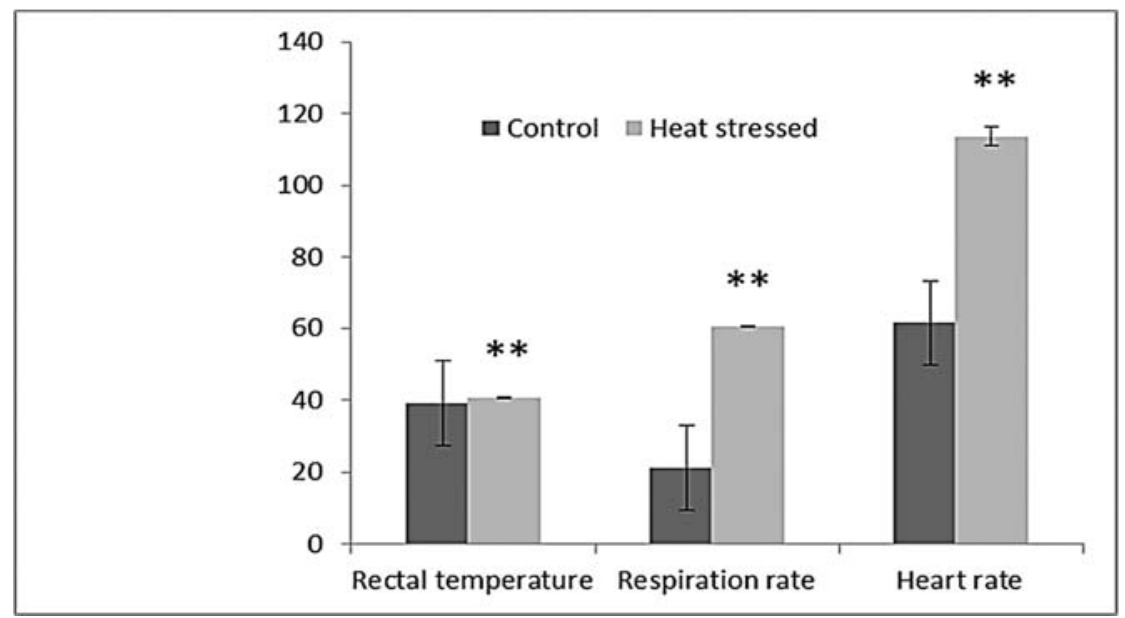

Figure (1): physiological parameters of clinically healthy and heat stressed goats. Note: $* *$ Significant at $p<$ 0.01 .

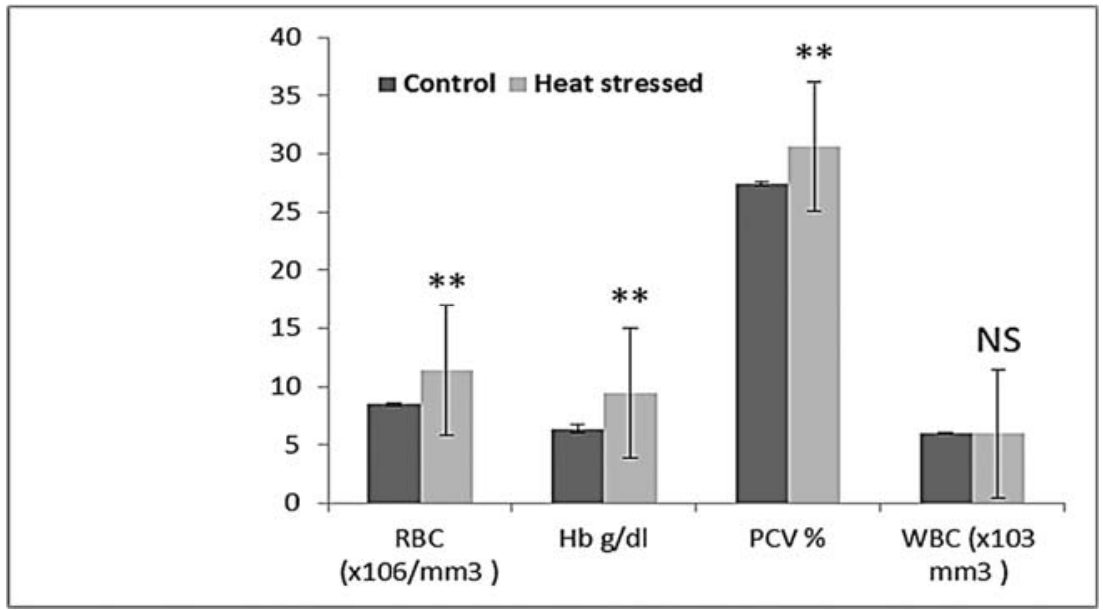

Figure (2): Hematological profile of clinically healthy and heat stressed goats. Note: ** Significant at $P<0.01$ and NS means Non-significant.

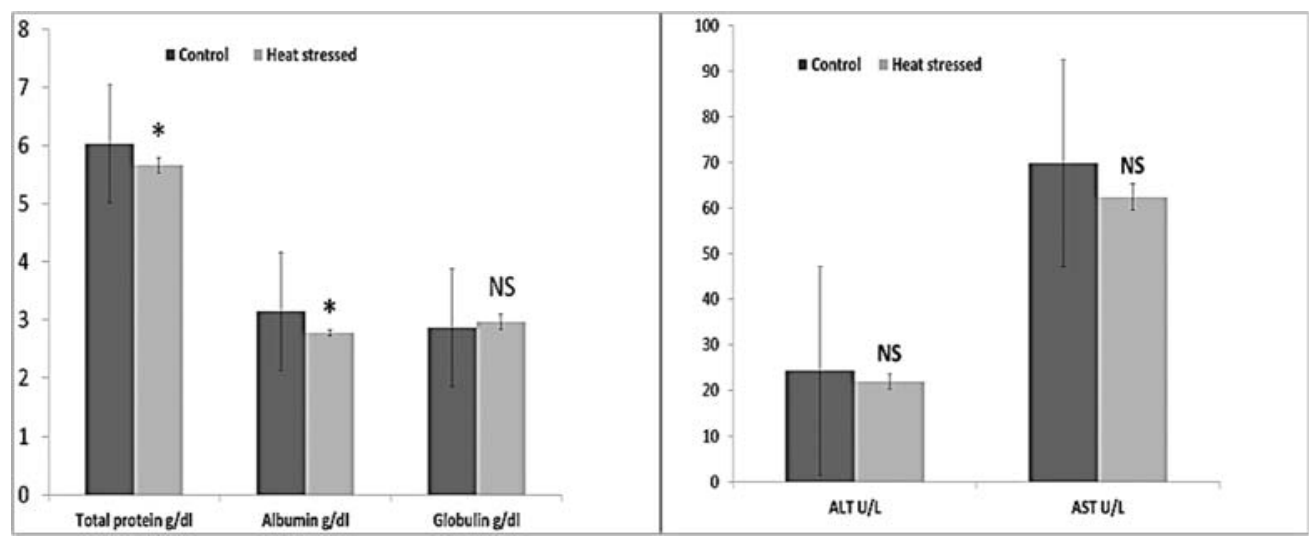

Figure (3): some hepatic biomarkers of clinically healthy and heat stressed goats. Note: * Significant at $P<$ 0.05 and NS means Non-significant . 


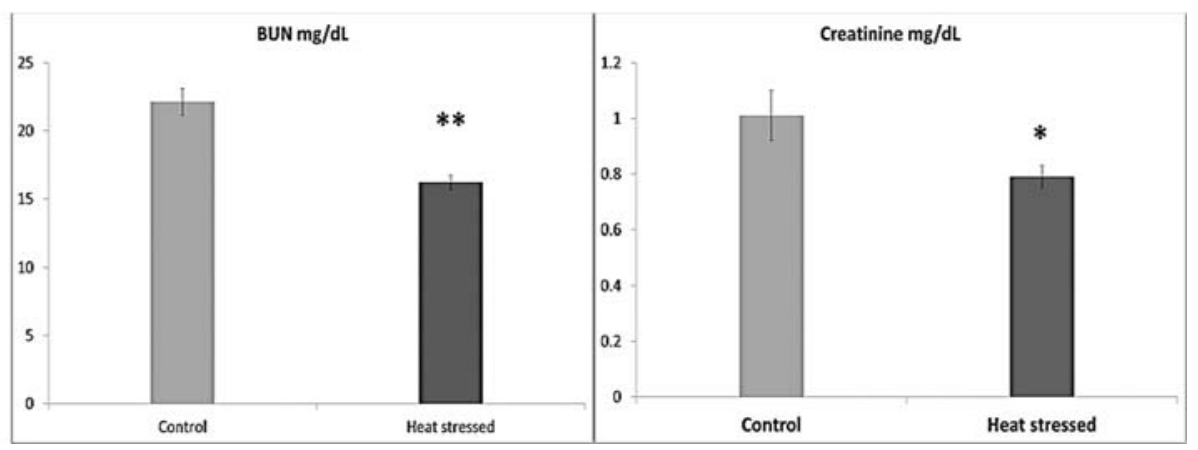

Figure (4): Blood urea nitrogen (BUN) and creatinine levels of clinically healthy and heat stressed goats. Note: * Significant at $P<0.05$; and ** Significant at $P<0.01$.

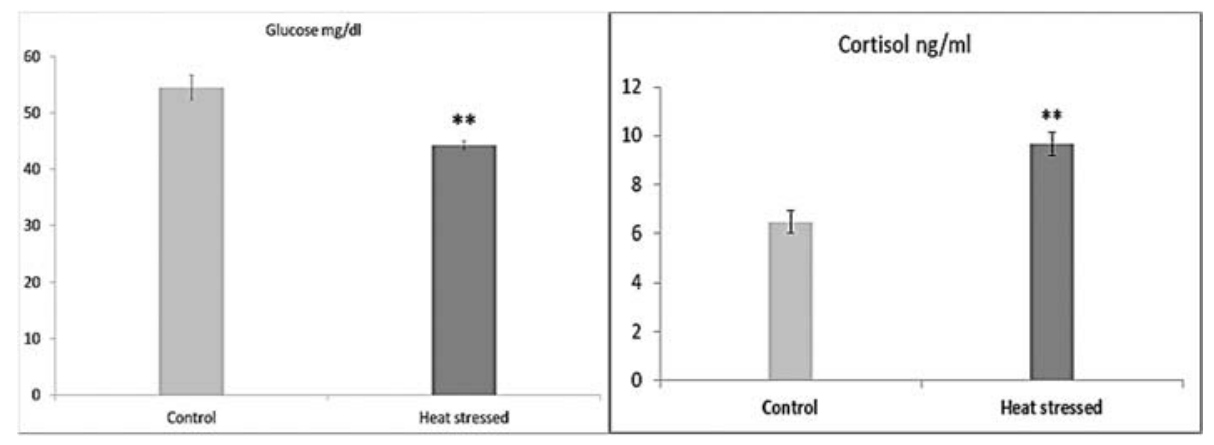

Figure (5): serum glucose and cortisol levels of clinically healthy and heat stressed goats. Note: ** Significant at $P<0.01$.

\section{DISCUSSION}

Heat stressed goats exhibited similar clinical signs as that recorded previously by Koluman and Daskiran (2011). Increase in environmental temperature has a negative effect on the appetite center of the hypothalamus causing the decrease of feed intake (Baile and Forbes, 1974). Reducing feed intake is a method of adaptation to decrease the heat production in warm environment as the heat increment of feeding is an important source of heat production in ruminants (Kadzere et al., 2002). Animals go into a stage of negative energy balance, hence body decreased. Increase the desire for water intake may be attributed to increase the body water retention that helps to ameliorate the rise in body temperature (Abdel-Samee et al., 2008). Salivation which observed in some cases may be considered as a method for decreasing the load of heat stress on the animal. While recumbency observed in severely affected animals due to the effect of heat stress on the muscular tone.

Physiological responses like rectal temperature, respiration rate and heart rate reflect the degree of stress imposed on animals (Ganaie et al., 2013). Rectal temperature is a good index of deep body temperature, which reflects thermal balance and might be used to evaluate the impact of heat stress (Srikandakumar et al., 2003).

The significant increase in rectal temperature attributed to the increased ambient temperature as Singh et al. (1980) found that raising the ambient temperature from 20 to $45^{\circ} \mathrm{C}$ resulted in increasing the rectal temperature by $1.4^{\circ} \mathrm{C}$ in sheep. Those results coincide with those of Alhidary et al. (2012); Manish et al. (2010); Marai et al. (2007).

Accelerated respiration rate occurs as the goats were found to rely primarily on respiratory activity as a principal mechanism for heat dissipation to control the body temperature under hot conditions and to counter balance the elevated heat load by evaporative cooling and vaporizing the high moisture content of the expired air. Similar results recorded by Sivakumar et al. (2010) and Manish et al. (2010). Respiration is the most sensitive physiological parameter to the change of climate and physical environment in ruminants (Sabuncuoglu, 2004). Respiration rate increases as a result of the activation of warm receptors in the skin when exposed to higher ambient temperature. Activation of these receptors, in turn, transmits neural signals to the hypothalamus that increases respiratory activity to hasten heat loss from the body by respiratory evaporation (Al-Haidary and Ahmed, 2004). An evaporative heat loss from the 
respiratory tract is regarded as one of the primary mechanisms for maintenance of heat balance to maintain the internal body temperature (Marai et al., 2007).

Hematological parameters are good indicators of physiological health status, and their evaluation is an important in assessing the response of the animal to various stressful conditions. As the levels of blood parameters reflect the metabolic activities during stress conditions. The significant elevation of $\mathrm{Hb}$ contents, $\mathrm{PCV} \%$ and $\mathrm{RBCs}$ count in heat stressed goats is in close agreement with the findings of Abdel-Samee et al. (1992) in goats, Srikandakumar et al. (2003) in sheep and AlHaidary (2004) who reported that exposure to heat stress resulted in a significant $(P<0.05)$ increase in packed cell volume (PCV). The higher PCV values had been reported to be an adaptive mechanism to provide the water necessary for evaporative cooling process (Al-Haidary, 2004). Although Sivakumar et al. (2010) measured that PCV and Hb were significantly decreased $(p<0.05)$ in the heat stress goats. While WBCs showed an insignificant change in heat- stressed group compared to the control one.

Glucose concentrations decreased markedly, along with high ambient temperature, which is consistent with previous reports (Alhidary et al., 2012; Bucklin et al., 1991) and this may be due to greater blood insulin activity (Baumgard and Rhoads, 2013; Rhoads et al., 2009) or could be due to reduced feed intake. Concentrations of serum total proteins and albumin have been used as indices for nutritional status. Serum total proteins and albumin concentration decreased during thermal stress in goats and our results were similarly to those of Sejian et al. (2013). Although there was no difference in globulin concentration of control and heat stressed group. Globulin level in blood plasma was insignificantly affected by season of the year (winter, summer and autumn) in rams under Egyptian conditions (Marai et al., 1992). Earlier studies in goats (Sejian et al., 2010) have also reported a significant decrease in total proteins, albumin and globulin concentration under heat stress. The decrease in plasma protein could be due to decrease in protein synthesis as a result of the decrease in the anabolic hormone secretion.

Serum enzymatic activity was measured to assist in the overall evaluation of the health status of the animal. Heat stress also decreased plasma aspartate aminotransferase (AST) and alanine aminotransferase (ALT) and the decreases in these enzymes are within the normal physiological limits (Duncan and Prasse, 1994). The decreases in these enzymes suggest that there is no liver damage, but rather a slowdown of the function of the liver when the animals were subjected to heat stress. Although serum ALT levels was increased during heat stress in goats while no change was observed in AST concentration in heat stressed goats (Sharma (Sharma and Kataria, 2011).

Regarding the results of renal function, a significant decrease in urea and creatinine in blood under heat stressful conditions, similar results obtained by (Abdel-Samee et al., 2008). This may be attributed to the decrease in ruminal ammonia $\mathrm{N}$ which is compensated by the more absorption of urea $-\mathrm{N}$ by rumen causing the decrease of blood urea and the increase of urinary nitrogen excretion these results were in agreement with Fike et al. (2005). Cortisol plays an important role in all types of stress as it is a classic endocrine response to stress (Kannon et al., 2000). It is used as an indicator of animal welfare, since its level increases during times of distress. A significant increase of cortisol in affected goats was well documented and our results coincided with earlier works (Caroprese et al., 2012; Sivakumar et al., 2010). It is indicated that there were significant deviations in the levels of blood biochemical which might be due to a metabolic shift in the stressed animals to cope with the imposed stress.

\section{CONCLUSION}

Heat stress is a combination of environmental conditions when the ambient temperature is higher than the temperature range of animal's thermoneutral zone. The heat stress has adverse effects on feed intake, growth rate, in addition, the haemato-biochemical profile of goats.

\section{REFERENCES}

Abdel-Samee, A., Kamal, T., Abu-Sinna, G., Hagag, A., 1992. Alleviation of the heat load on lactating goats with the use of diuretics and drinking cool water. Beitr. Trop. Landwirtsch. Veterinarmed. 30, 91-99.

Abdel-Samee, A.M., Abd-Alla, O., EL-Adawy, S., 2008. Nutritional Treatments for Alleviation of Heat Stress in Awassi Sheep Using Acacia and Olive Pulp in Subtropics. Egypt. J. Comp. Path. \& Clinic. Path. 21, 466- 477.

Al-Haidary, A., 2004. Physiological responses of naimey sheep to heat stress challenge under semi-arid environments. Int. J. Agric. Biol. 6, 307-309.

Al-Haidary, A., Ahmed, A., 2004. Physiologic response of Niamey sheep to heat stress 
challenge under semi-arid environment. Int. J. Agric. Biol. 2, 307-309.

Al-Tamini, H., 2007. Thermo regulatory response of goat kids subjected to heat stress. Small Rum. Res. 7, 280-285.

Alhidary, I.A., Shini, S., Al Jassim, R.A., Gaughan, J.B., 2012. Physiological responses of Australian Merino wethers exposed to high heat load. J Anim Sci 90, 212-220.

Avendono-Reyes, L., Hernandez-Rivera, J., Alvaraze-Valenzuela, F., Macias-Cruz, U., Diaz-Molinar, R., Correa-Calderon, A., Robinson, P., Fadel, J., 2011. Physiological and productive responses of multiparous lactating Holstein cows exposed to short term cooling during severe summer conditions in an arid region of Mexico. Int. J. Biomet. .

Baile, C.A., Forbes, J.M., 1974. Control of feed intake and regulation of energy balance in ruminants. Physiol Rev 54, 160-214.

Baumgard, L.H., Rhoads, R.P., Jr., 2013. Effects of heat stress on postabsorptive metabolism and energetics. Annu Rev Anim Biosci 1, 311-337.

Bucklin, R., Turner, L., Beede, D., Bray, D., Hemken, R., 1991. Methods to relieve heat stress for dairy cows in hot, humid climates. Appl. Eng. Agric. 7, 241-247.

Caroprese, M., Albenzio, M., Bruno, A., Annicchiarico, G., Marino, R., Sevi, A., 2012. Effects of shade and flaxseed supplementation on the welfare of lactating ewes under high ambient temperatures. Small Ruminant Research 102, 177-185.

Dash, S., Chakravarty, A.K., Singh, A., Upadhyay, A., Singh, M., Yousuf, S., 2016. Effect of heat stress on reproductive performances of dairy cattle and buffaloes: A review. Vet World 9, 235-244.

Duncan, J., Prasse, K., 1994. Veterinary Laboratory Medicine, 3rd ed. Iowa State Univ. Press, 10 Ames.

Fike, J., Saker, K.E., Fonte-not, J., Veit, H., 2005. Effect of Tasco (a seaweed extract) and heat stress on $\mathrm{N}$ metabolism and meat fatty acids in wether lambs fed hays containing endophyte-infected fescue. Small Rumin Res. 60 , $237-245$.

Ganaie, A., Shanker, G., Nazir, A., BumlaGhasura, R., Mir, N., Wani, S., Dudhatra, G., 2013. Biochemical and physiological changes during thermal stress in bovines. J. Vet. Sci. Technol. 4, 1-6.

Jackson, P., Cockcroft, P., 2008. Clinical Examination of Farm Animals, 1st ed. John Wiley \& Sons, New York, NY.
Kadzere, C.T., Murphy, M.R., Silanikove, N., Maltz, E., 2002. Heat stress in lactating dairy cows: a review. Livestock Production Science 77, 59-91.

Kannon, G., Terril, T., Kouakou, B., Gazal, O., Gelaye, S., Amoah, E., Samake, S., 2000. Transportation of goats: effect on physiological stress responses and live weight loss. J. Anim. Sci. 78, 1450-1457.

Koluman, N., Daskiran, I., 2011. Effects of ventilation of the sheep house on heat stress, growth and thyroid hormones of lambs. Trop Anim Health Prod 43, 1123-1127.

Manish, K., Jindal, R., Nayyar, S., Singla, M., 2010. Physiological and biochemical responses in Beetle goats during summer season. Ind. J. Small Rum. 16, 255-257.

Marai, I., Bahgat, L., Shalaby, T., Abdel-Hafez, M., 2000. Fattening performance, some behavioral traits and physiological reactions of male lambs fed concentrates mixture alone with or without natural clay, under hot summer of Egypt. Ann. Arid Zone 39, 449460.

Marai, I., Daader, A., Makkawy, M., Gabr, H., Ibrahim, H., 1992. Effect of housing system, season of year and age on some physiological parameters and blood constituents of Ossimi sheep. J. Arid. Environ. 22, 277-285.

Marai, I.F.M., El-Darawany, A.A., Fadiel, A., Abdel-Hafez, M.A.M., 2007. Physiological traits as affected by heat stress in sheep - A review. Small Ruminant Research 71, 1-12.

Reuter, A.M., Ketelslegers, J.M., Hendrick, J.C., Franchimont, P., 1978. Radioimmunoassay of protein hormones: principles and methodology. Horm Res 9, 404-421.

Rhoads, M.L., Rhoads, R.P., VanBaale, M.J., Collier, R.J., Sanders, S.R., Weber, W.J., Crooker, B.A., Baumgard, L.H., 2009. Effects of heat stress and plane of nutrition on lactating Holstein cows: I. Production, metabolism, and aspects of circulating somatotropin. J Dairy Sci 92, 1986-1997.

Sabuncuoglu, N., 2004. Effect of barn types on physiological traits of calves. Ind. Vet. J. 81, 22-24.

Sejian, V., Indu, S., Naqvi, S.M.K., 2013. Impact of short term exposure to different environmental temperature on the blood biochemical and endocrine responses of Malpura ewes under semi-arid tropical environment. Indian Journal of Animal Sciences 83, 1155-1159.

Sejian, V., Srivastava, R., Varshney, V., 2010. Effect of short term thermal stress on 
biochemical profile in Marwari goats. Ind. Vet. J. 87, 503-505.

Sharma, A.K., Kataria, N., 2011. Effect of extreme hot climate on liver and serum enzymes in Marwari goats. Indian Journal of Animal Sciences 81, 293-295.

Sivakumar, V., Singh, G., Varshney, V., 2010. Antioxidants Supplementation on Acid Base Balance during Heat Stress inGoats. AsianAust. J. Anim. Sci. 23, 1462-1468.
Snedecor, G., Cochran, P., 1989. Statistical Methods, 8th ed. Lowa State University, Press, Ames, IA.

Srikandakumar, A., Johnson, E.H., Mahgoub, O., 2003. Effect of heat stress on respiratory rate, rectal temperature and blood chemistry in Omani and Australian Merino sheep. Small Ruminant Research 49, 193-198.

Sugiura, M., Hirano, K., 1977. A new colorimetric method for determination of serum glucose. Clin Chim Acta 75, 387-391. 